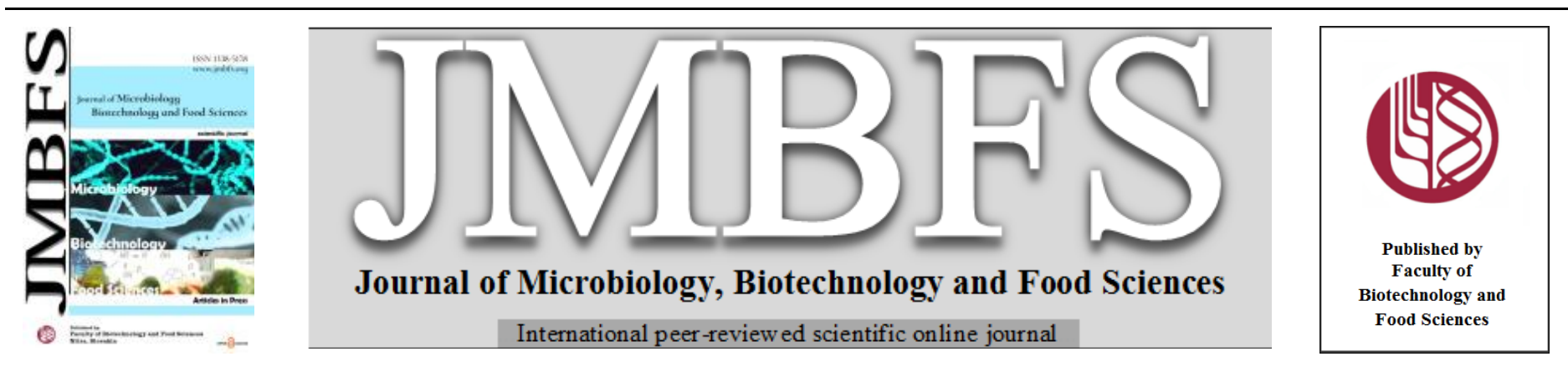

\title{
USE OF BACTERIOPHAGES AS A TARGET SPECIFIC THERAPY AGAINST FOOD-BORNE PATHOGENS IN FOOD INDUSTRY- A REVIEW
}

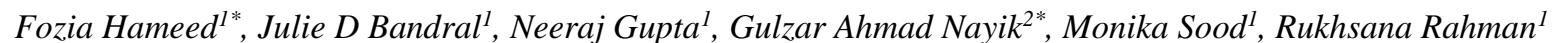

Address(es):

${ }^{1 *}$ Division of Food Science and Technology, SKUAST-Jammu, Chatha, J\&K, India-180009.

${ }^{2 *}$ Department of Food Science \& Technology, Govt. Degree College, Shopian, J\&K, India-192303.

*Corresponding author: cgulzarnaik@gmail.com and S.fozia011@gmail.com

https://doi.org/10.55251/jmbfs.2949

\section{ARTICLE INFO}

Received 12. 4. 2020

Revised 3. 9. 2021

Accepted 6. 9. 2021

Published 1. 2. 2022

Regular article

OPEN $\partial_{\text {ACCESS }}$

\begin{abstract}
Within the context of food safety, the use of modern antimicrobial technologies to inactivate the food-borne pathogens is not infallible, as proven by the ceaseless increase in the food-borne illnesses. The extensive use of antibiotics to minimize the microbial contamination further results in the evolution of antibiotic-resistant bacterial pathogens. Moreover, some of the decontamination methods frequently used in the food industry cannot be directly applied to fresh fruits and vegetables, and RTE meals. Therefore, efforts are being made by researchers in developing a new approach so as to control the bacterial contamination. Consequently, bacteriophages have evolved as the safe, green, effective and natural alternative for treatment and complete destruction of pathogens in food industry. The review provides a general description about bacteriophages and has mainly focused on their potential use as antimicrobials during the postharvest processing of foods. Numerous research papers, review papers, book chapters and other relevant literature was used for writing this review paper.
\end{abstract}

Keywords: bacteriophages; food-borne illnesses, bacterial pathogens, phages, antimicrobial, food safety; food industry

\section{INTRODUCTION}

Food is the basic necessity of day-to-day life and foods, such as fresh and frozen products, ready to eat foods, pre-cooked meals and so on, meant for consumption, always remain under constant threat due to contamination by pathogenic bacteria. Today's consumer is increasingly looking for "green appeal" in their food products (Atchley, 2019). There is a growing trend towards the purchase of food products that are not treated with chemical sanitizers or antibiotics and that are sustainably and naturally grown and processed, including not "genetically modified" (Lewis and Hill, 2020). Nevertheless, the use of modern disinfection methods like pasteurization, high hydrostatic pressure processing (HHP), irradiation therapy, sanitizing chemicals (chlorine and peracetic acid) and so on reduce the microbial population in foods to a great extent (Sohaib et al., 2016) but also have some disadvantages suchlike high initial outlay, destruction of the processing equipment owing to their caustic nature and most importantly cause detrimental changes in the nutritional as well as organoleptic qualities of food (Moye et al., 2018). Every year, an estimated 600 million individuals - nearly one out of every ten people on the planet - become unwell after eating contaminated food, with 420000 deaths, resulting in the loss of 33 million healthy life years.US $\$ 110$ billion is lost each year in productivity and medical expenses resulting from unsafe food in low- and middle-income countries Foodborne sickness affects $40 \%$ of children under the age of five, resulting in 125000 fatalities each year (WHO, 2020). Keeping in view all the factors, the need of the hour is the use of the technique that has a targeted antimicrobial approach, thereby, improving food safety (Hudson et al., 2005). One such promising technique often been the subject of increasing interest is the use of bacteriophages, a green and natural approach, particularly to target food-borne pathogenic bacteria without affecting the beneficial microflora and hence eliminate them from food.

The obligate intracellular parasites (viruses) that often infect and kill solely bacteria are known as bacteriophages (or phages). The term "bacteriophage" has been derived from bacteria and "phagein" that means to eat/to devour in Greek (Orlova, 2012). Bacteriophages are widespread in nature, being abundant in saltwater, freshwater, soil, plants and animals, in which their bacterial hosts reside (El-Shibiny and El-Sahhar, 2017). Except for their target bacterial hosts, phages are innocuous for all organisms including humans, maintaining its microbia balance. Phages reproduce by hijacking their host's biosynthetic pathways. A total of $10^{32}$ bacteriophages have been identified (Wommack and Colwell, 2000) and over 6000 have been morphologically described so far (Ackermann and Prangishvili, 2012). Majority of them belong to the Myoviridae, Siphoviridae and Podoviridae families. Phages have been known for a century ago. A British bacteriologist namely Ernest Hanbury Hankin, in 1896 first reported bactericidal activity of bacteriophages when the filtered water from Ganga and Jamuna rivers in India were found to have antibacterial activity against Vibrio Cholera. His work was first published in the Annals of the Pasteur Institute in French. Later in 1915 , Frederick Twort, a British microbiologist, described the antimicrobial activity of bacteriophages while studying the vaccinia virus growth on cell-free culture media. After two years in 1917, Flix d'Herelle use bacteriophages for the treatment of dysentery for therapeutic purposes. But with the discovery of antibiotics the use of phages was nearly wiped out. However efficacy of using antibiotics was lost due to bacterial resistance to antibiotics (Fair and Tor, 2014). Later in 1980's, phage inactivation of E.coli in mice demonstrated the efficacy of bateriophages as compared with the use of antibiotics.

\section{Phage biology and classification}

Bacteriophages are relatively inert biological entities composed of DNA and RNA genome encapsulated in a protein capsid. Morphologically, phages exhibit a distinct three dimensional structure, as illustrated in Fig. 1., consisting of 1) Head or capsid, usually icosahedral, built of structural proteins and nucleic acid (DNA or RNA) as a carrier of genetic information. 2) Tail, consisting of tail tube surrounded by spiral contractile sheath. Both tail tube and helical sheath are attached to dome shaped baseplate. 3) Tail fibers, six in number are folded beneath the baseplate, entirely made of proteins that are responsible for identifying the specific molecules at the surface of host bacterium. 4) Baseplate, a hexagonal dome like structure composed of 15 different proteins called as host cell or receptor binding proteins (Leiman and Shneider, 2012). The central hub of the base-palte comprises of gp5-gp27 complex (Leiman et al., 2010). 


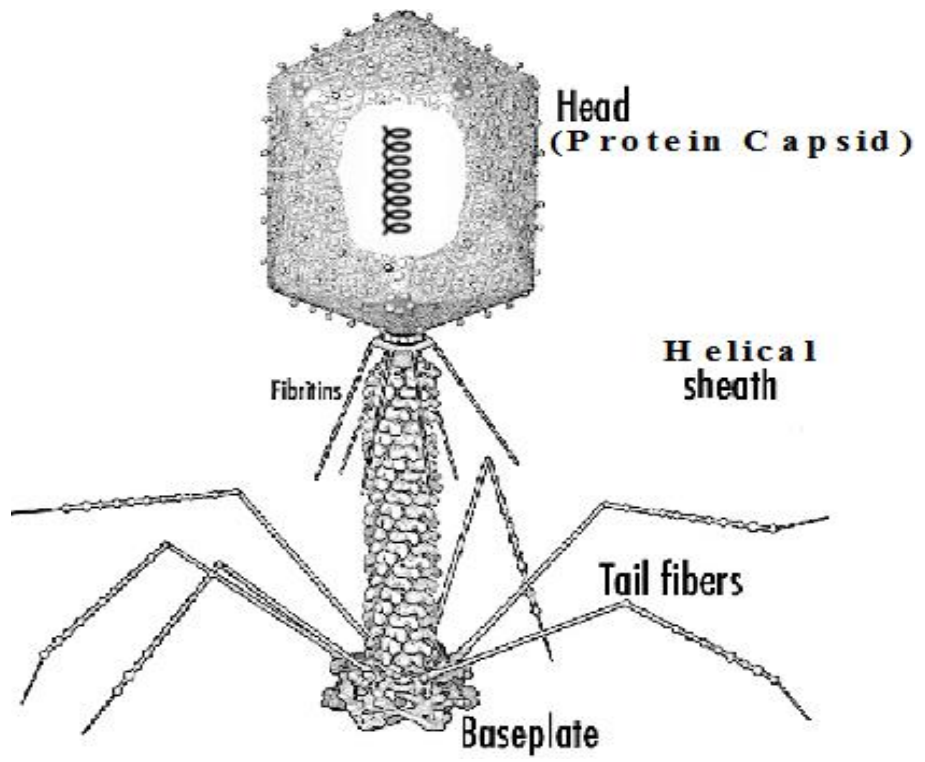

The icosahedral protein capsid surrounds the phage nucleic acid (DNA or RNA), which is adhered through a collar to its helical sheath. At the distal extremity of helical sheath is situated a dome shaped basal plate. The hexagonally shaped baseplate coordinates the motion of six tail fibers, responsible for sensing the presence of bacterial host cell. The tail fibers (short) unfolding from beneath the basal plate firmly adhere toits host and the helical sheath that surrounds the tail tube contracts, thus discharging its DNA inside the bacterium. Adapted from Harada et al., 2018Since the past fifty years, about 6000 phages have been identified and morphologically studied, vast majority of these bacteriophages $(96 \%)$ are tailed and others (3.7\%) polyhedral, filamentous or pleomorphic and belongs to families such as Myoviridae, Siphoviridae and podoviridae (Ackerman, 2007; Wittebole et al., 2013) (Table 1.). They are classified on the basis of their morphology, genetic material, living habitat, specific host and life cycle. Depending upon the genetic material (DNA or RNA) packed within the polyhedral protein capsid, prototypical bacteriophages can be divided into four groups (Fig. 2): ssDNA (single stranded DNA) tailed phages, dsDNA (double stranded DNA) tailed phages, ssRNA (single stranded RNA) tailed phages, and dsRNA (double stranded RNA) tailed phages. On the basis of the capsid symmetry, phages are classified as: isometric (polyhedral) and helical (spiral).

Figure 1 Pictorial illustration of a typical phage particle.

Table 1 An overview of major bacteriophage types (Modified from Ackermann, 2009 and Harada et al., 2018).

\begin{tabular}{llcccc}
\hline Shape & Phage family & Nucleic acid (DNA or RNA) & Features & Example \\
\hline \multirow{3}{*}{ Tailed } & Myoviridae & double stranded DNA, linear & contractile long tail & T4 \\
\cline { 2 - 6 } & Siphoviridae & & noncontractile long tail & $\lambda$ \\
\cline { 2 - 6 } & Podoviridae & & noncontractile short tail & T7 \\
\hline \multirow{4}{*}{ Polyhedral } & Microviridae & single stranded DNA, circular & tailless isometric phages & $\varphi$ X174 \\
\cline { 2 - 6 } & Corticoviridae & double stranded DNA, circular & tailless isometric phages & PM2 \\
\cline { 2 - 6 } & Tectiviridae & double stranded DNA, linear & pseudo-tailed phages & PRD1 \\
\cline { 2 - 6 } & Leviviridae & single stranded RNA, linear & tailless isometric phages & MS2 \\
\cline { 2 - 6 } & Cystoviridae & double stranded RNA, linear, segmented & tailless spherical phages & $\varphi 6$ \\
\hline Filamentous & Inoviridae & single stranded DNA, circular & tailless long filamentous phages & fd \\
\hline \multirow{2}{*}{ Pleomorphic } & Plasmaviridae & double stranded DNA, circular, & tailless pleomorphic phages & \multirow{2}{*}{ MVL2 } \\
& & superhelical & &
\end{tabular}
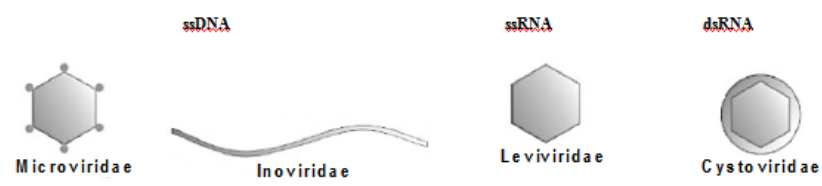

dsDNA
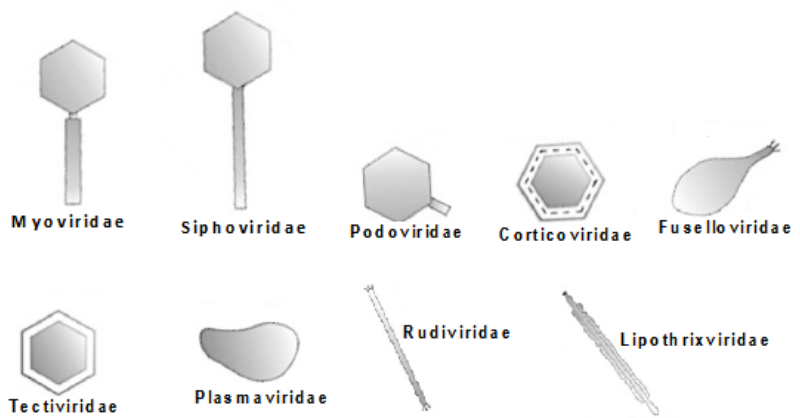

Figure 2 Bacteriophage classification based on their morphology and genetic content (DNA or RNA). Adapted from Ackerman, 2007 and Hanlon, 2007.

In relation to the type of phage lifestyle they exhibit within its bacterium hos surface, bacteriophages are of two types: virulent and temperate. Virulent phages (displaying a lytic life cycle) are so called because they take over the bacterial host metabolism, directing the production of new virions and then lyses the cell once the viral progeny is released (El-Shibiny and El-Sahhar, 2017). Temperate phages (displaying a lysogenic life cycle) incorporate their genetic material within the bacterium. The genetic material of phage remains inactive in the host cell becoming a prophage and reproduces within the host until the lytic cycle is introduced. Whether or not to establish a prophage state, this decision is made by the temperate phage after infection (Weinbauer, 2004).

\section{BACTERIOPHAGE LIFE CYCLE}

Subsequently after the attachment of the phage to its host, tail spike on the baseplate of bacteriophage enters into the host and release genome of bacteriophage into the bacterial host cell. As intracellular obligate parasites, phage particles exhibit a lytic or a lysogenic life-cycle after the bacterial infection Furthermore, phages cause lysis of the host cell as a result of two mechanisms: "lysis from within" where the bacterial host lysis is induced due to phage replication and "lysis from without" where the lysis occurs in absence of phage replication. In this case the cell lysis occurs due to bacteriophage cell wall degrading enzymes or difference in membrane electric potential (Andreoletti et al, 2009). In lytic life cycle, the bacteriophage genome occurs as a separate free floating molecule inside the host and reproduces from the host DNA separately. Basically lytic cycle is a six stage cycle with steps viz: 1) Attachment, where bacteriophage first adheres itself to the host cell. 2) Penetration, where bacteriophage inserts the genome within the bacterial host. 3) Transcription, where the genome of the host cell is degraded, thus, directing the phages molecular machinery to initiate phage biosynthesis. 4) Biosynthesis, where bacteriophage nucleic acid replicates within host and synthesize new virions. 5) Maturation, assembly of the phage particles each made of head, tail and tail fiber. 6) Lysis, where the new virions burst from the host cell into the environment (Fig. 3a) (Burmeister et al., 2019). Example of the phage undergoing lytic cycle include phage $\mathrm{T} 2$.

In contrast, lysogenic life cycle is stable and the pahge is unable to replicate until provided with necessary conditions such as exposure to mitomycin C or UV radiation (Hudson et al., 2005). During the lysogenic cycle the phage undergoes following steps: 1) Adsorption of phage to the receptor of host cell surface. 2) Penetration of viral DNA into the bacterial chromosome. 3) Formation of prophage by recombination. 4) Cell division of the lysogenic bacterium. 5) Biosynthesis of new phage DNA via a lytic pathway. 6) Assembly of the phage particles into new virions. 7) Lysis of the cell followed by release of the virions into the extracellular environment (Fig. 3b). Example of phages undergoing lysogenic cycle are phage P1 and phage $\lambda$.

However, in either case, perforation of the membrane occurs by the holins (products of old bacteriophage particles) so as to release new phage particles and thus facilitate the translocation of lysins to the cell wall (peptidoglycan layer). The cell wall is degraded, resulting in lysis of the host with concurrent release of the new phages into the extracellular environment (Maura and Debarbieux, 2011; Smith and Trevino, 2009). 


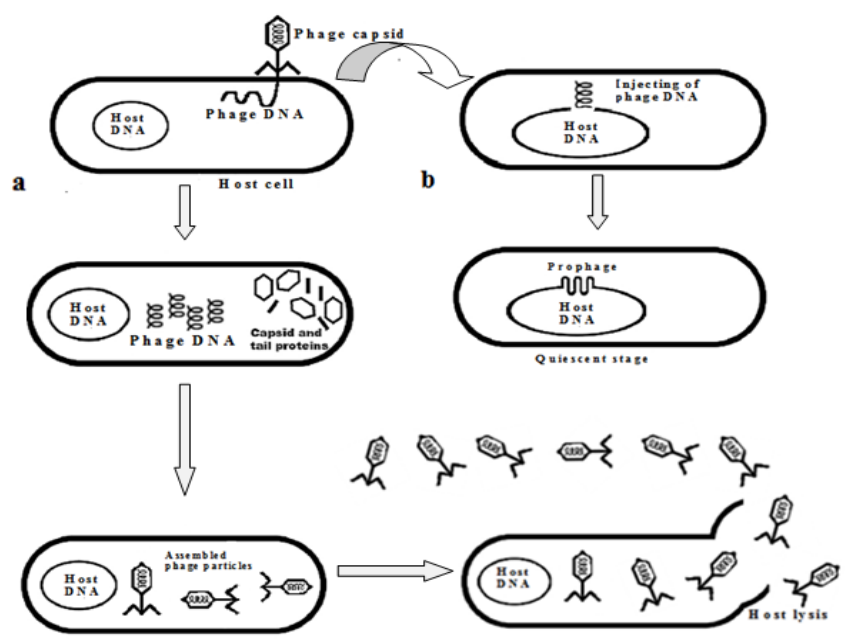

Figure 3 Diagrammatic representation of (a) lytic and (b) lysogenic cycle of the bacteriophage. Adapted from (Harada et al., 2018) with some modification.

\section{MECHANISM OF PHAGE-CELL SURFACE INTERACTION}

The baseplate, a hexagonal dome-shaped part in the bacteriophage, coordinates the bacterium cell recognition and adhesion with the contractile sheath. This process starts at basal plate and propagates amid the whole contractile sheath length in a wavelike fashion (Harada et al., 2018). Furthermore, tail fibers usually six in number, emerging from the baseplate determine the bacterial host cell specificity and the part of fibers responsible for bacterial host binding lies 1,000 $\AA$ away from baseplate in certain bacteriophages. However the successful binding of the phage to the bacterial host surface receptor results in the structural transition of the baseplate from a hexagonal dome-shaped to a planar star-shaped structure, ultimately causing sheath contraction (length decreases from $925 \AA$ to $420 \AA$ while diameter increases from $240 \AA$ to $330 \AA$ ) (Aksyul et al., 2009). Consequently, the bacterium-binding signal must be propagated throughout the whole tail fiber to the basal plate of bacteriophage, which (signal transmission) occurs as a result of change in conformation of the tail fibers with respect to baseplate. The phage tail fibers does not exhibit a fixed position, thus point themselves either sideways or towards the protein capsid. This happens when the bacteriophages are free in aqueous or buffer solutions but the tail fibers of the phage particle bound to the bacterium surface point toward it. There are two possible mechanisms, widely accepted nowadays, that will explain how and why suchlike tail fiber conformational changes took place only on bacterium surface but not in the aqueous or buffer solution when the phage is free (Fig. 4) especially when no chemical energy is used in tail fiber reorientation and basal plate triggering (Leiman and Shneider, 2012).

The first hypothesized mechanism which is most widely approved rationalize that when phage particles come through an infected bacterial host cell, only one or two fibers of the bacteriophage interact with lipopoly-saccharide host surface receptors (Leiman et al., 2004). The host adhered phage now comes under the influence of solvents resulting from cell swimming and other molecular motions of Brownian, thermally induced, convective currents movements and so on. Bacteriophage is tethered to the host surface murein receptors through its long tail fibers, whilst being constantly vibrated to and fro by movements of solvent (Harada et al. 2018). Ultimately, the remaining fibers of phage chain themselves to host cell membrane receptors, thus, configuring the phage particle perpendicular to the surface of bacterial cell membrane along with concurrent orientation of all long fibers to be positioned towards the host cell, hence forming more new interactions in the phage baseplate. This configurational change results in switching to a conformation with low energy, thus, unlocking tail sheath to contract (Leiman and Shneider, 2012). Though, the spontaneous tail contraction does not happen due to configuration of the phage fibers related with the extended and contracted three dimensional tail sheath conformation are separated by a remarkable difference in the free energy (Gibbs free energy, $\Delta \mathrm{G}$ ) peak. This variation in the high free energy can be overcome if only the tail fibers of the phage particles become paralyzed on host membrane, while as bacteriophage is being constantly shaken by the solvent (Kostyuchenko et al., 2005).

Other possible interpretation of how reorientation of phage fiber can be linked to contraction of tail sheath when attached to the bacterial host surface comes from the observation that numerous phages necessitate divalent cations $\left(\mathrm{ca}^{2+}\right)$ for bacterial infection. Phage receptors such as polysaccharides and protein molecules present on the host membrane surface bind those ions, thus, rising their concentration near the surface of the host cell. Such huge concentration of the calcium ions near the cell surface brings about the configurational changes in the dome shaped baseplate followed by propagation of tail fibers to adhere to the cell surface. The three dimensional arrangement of basal plate will then change, thus unlocking the tail sheath to contract. The similar mechanism was put forward by Sciara et al., 2010 in his work entitled "Structure of lactococcal phage p 2 baseplate and its mechanism of activation". His work was published in Proceedings of the National Academy of sciences (PNAS). The findings of his study revealed that Gram positive Lactococcus lactis bacteriophage $\mathrm{p} 2$ requires divalent calcium ions for infection.

Possibly both the proposed mechanisms work simultaneously. As earlier discussed, due to the solvent induced phage drifts, the tail fibers point themselves towards the host cell surface followed by change in the baseplate configuration as a result of surface associated ions. However, the contraction of the sheath leads to the movement of the capsid and tube to come closer towards the host cell membrane followed by puncturing the host cell membrane with central baseplate spike protein, driven by the energy of the phage tail sheath. Thus, causing the genetic material of the bacteriophage to eject from the tube into bacterium cytoplasm. Leiman et al., 2004 mentioned that contraction of the tail sheath and ejection of the phage DNA are not linked because the phage contraction may be due to subjecting the phage to osmotic shock. Furthermore, contracted tail phages are relatively stable and do not release their genetic material (DNA). This means that a specific receptor must be present on host cytoplasmic membrane for unlocking the tube, thus, allowing the genome (DNA) release into bacterium cytoplasm. Phage tail tube unlocking likely be due to specific lipids of which the membrane is made. Ultimately the next step in the infection process is the translocation of phage DNA through the tail tube into the bacterium (Harada et al., 2018).
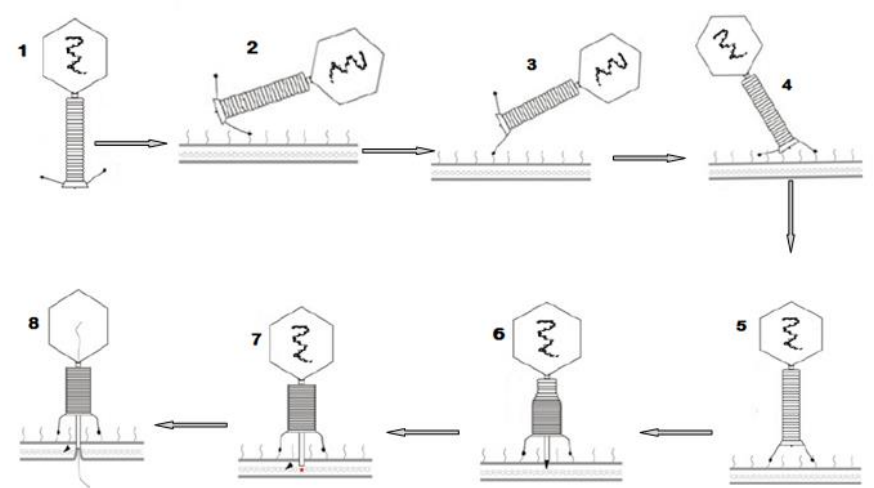

Figure 4 Diagrammatic representation of the putative adsorption mechanism of phage to its host during the process of infection.

In Fig. 4(1) The phage is unbound in the solution moving its long fibers freely based on the motion of solvent. Fig. 4(2) The phage particle bind itself to the surface of bacterium with only one or two of its tail fibers. Bacteriophage now is chained to the bacterium cell surface through its long fibers restricting the movement of phage particle. Fig. 4(3) The phage particle drifts in such a manner so that tail fiber acquires a conformational change where from it cannot shift back to the free phage particles, forming new relations with basal plate receptor binding proteins and thus initiating configurational change in the baseplate. Fig. 4(4) Whilst being connected to the bacterium cell surface through its tail fibers, the phage particle continues hula-hula, kind of dance on the host cell surface with concomitant binding of the other tail fibers with their respective partners on the host cell surface. Fig. 4(5) All the tail fibers of the phage are now bound to the hos cell receptors, thus configuring phage perpendicular to the surface of host cell membrane with concurrent orientation of all long tail fibers in the direction of host cell. Fig. 4(6) The continual conformational changes in the baseplate initiates tail sheath contraction, driving the phage protein capsid and tube towards bacterium cell membrane followed by puncturing the host cell membrane with central baseplate spike protein. Fig. 4(7) the spike protein thus separate from the tube tip and open the tube channel. The glycosidase associated with tail cause a small hole in the host cell surface peptidoglycan layer. Fig. 4(8) At the end the tube binds with the host's inner membrane in the final stage of infection, further pushing the membrane towards the tail tube by cytoplasmic osmotic pressure in the small region where peptidoglycan layer is lacking with concomitant release of DNA into the host's cytoplasmic environment.

\section{PHAGE APPLICATIONS ALONG THE FOOD CHAIN}

Regardless of the advances in the novel technologies and GMPs (good manufacturing practices), quality control and hygiene, for controlling microbial contamination, food safety is continuously challenged in the agri-food sector due to change in consumer lifestyle and increased consumer demand for chemical free organic food (Sillankorva et al., 2012). Thereby, phages (environmentallyfriendly) have been emerged as a promising green and novel approach with an effort to control the microbial contamination as well as to prevent the microbial spoilage. In the farm-to-folk context, phages can be used at each stage such as from 
the decontamination of farm animals to biocontrol in raw meats and fresh produce, to sanitation of food processing equipments and contact surfaces and also as natural food preservatives (Fig. 5) (Endersen et al., 2014). As far as food safety is considered, lytic phages are the most safe antibacterial agents available and can be utilized both at pre-harvest (e.g., in farm animals, dispensed via animal feed or sprayed before slaughter) and post-harvest (e.g., direct spraying on the surface of food, applied via packages, or by any other means) so as to minimize the bacterial contamination (Sulakvelidze, 2013)

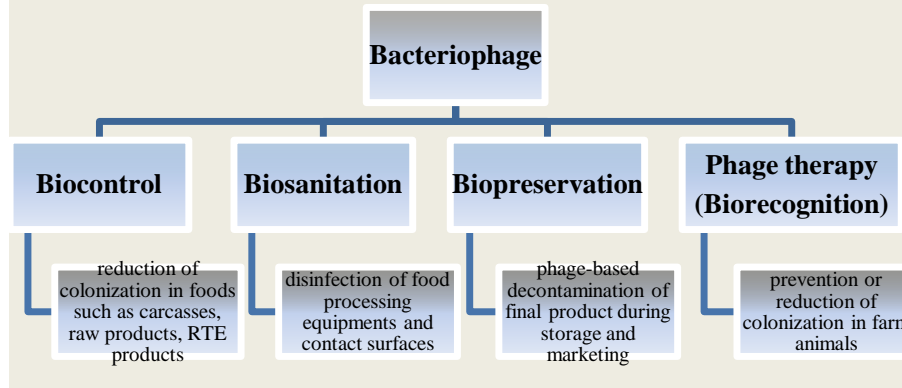

Figure 5 Applications of bacteriophages during the farm-to-fork continuum (Adapted and modified from Sillankorva et al., 2012).

Application of the phage and their lysins as biocontrol agents for food safety applications has been reviewed by Coffey et al., 2010. Phages and their lysins offer great advantages as biocontrol agents in foods, however, scientific evidences indicate that the pros of phages outrank the cons. The use of the phages is considered safe. Indeed, the United States Food and Drug Administration (USFDA) has enumerated some bacteriophages with Generally Recognized As Safe (GRAS) status, to arrest microbial (Escherichia coli, L. monocytogenes, Salmonella and so on) growth in the food products and food processing facilities. However, till date, no scientific literature unveil the harmful effects of phages on humans as well as animals, even when the phages were used at therapeutic doses (Mahony et al., 2011). A study carried out by Carlton et al., 2005 concluded that when phage (p100) @ $5^{\times} 10^{11} \mathrm{PFU} / \mathrm{ml}$ phage preparation was orally administered to Wistar albino rats over a five day period, no effect on the physical appearance and rodent behavior was observed. According to another study conducted by Bruttin and Brussow, 2005, no adverse effects related to application of phage were found on the fifteen healthy adult volunteers after the oral administration of Escherichia coli bacteriophage T4 at lower @ 103 PFU/ml and higher doses @ 10 $\mathrm{PFU} / \mathrm{ml}$ through their drinking water. Hence, it is evident that the results of the studies give quite convincing proof in assessing the safety of the phages as biotherapeutics.

Advantages and disadvantages of phage biocontrol agents

Advantages

- Host specificity means target only bacterial pathogen of interest

- $\quad$ Self-replicating at the infection site

- Safe, effective and stable while in use due to their nucleic acid and protein composition

- Abundant in both terrestrial and aquatic habitat

- All natural, non-toxic and profitable

- $\quad$ Easy to isolate and propagate

- No effect on the sensory and nutritional quality of food

Disadvantages

Antibacterial agents and also disrupt biofilms.

- $\quad$ Emergence of phage-neutralizing antibodies

- Sensitive to commonly used disinfectants

- Require low temperature storage

- Narrow host range

- $\quad$ Lacking of phage biology knowledge at users end

- Negative consumer perception concerning the use of "viruses" in food products

- $\quad$ Possible transfer of antibiotic resistance genes by phages to bacterial strains

Bacteriophages are the most abundant self-replicating entities that are widely distributed in the natural habitat. For example a viable count of about $10^{8}$ phage/gram are present on the fresh and processed meat and meat products. Phages offer an extreme specificity to target their bacterial host, one of the most significant advantages of bacterial pathogen biocontrol and because of their inherent hos specificity, phages harbor a targeted antimicrobial approach without affecting the beneficial microorganisms in the environment (Guenther and Loessner, 2011) Phages are consumed regularly via various foods because they form part of the natural microbial flora found in foods.

\section{PHAGE-BASED DECONTAMINATION OF POSTHARVEST FOODS}

Foods are more susceptible to bacterial contamination as well as spoilage postharvest and their consumption leads to many food-borne outbreaks. Postharvest controlling of the bacterial pathogens is a complex process. Although the traditional preservation techniques like pasteurization, high pressure processing (HPP), irradiation and chemical sanitizers result in the devastation of microbial population indiscriminately, destroying both pathogenic as well as beneficial bacteria. To overcome the problem, phage therapy (novel and green technique) being target specific, is effective in eradicating or preventing the pathogen contamination associated with food and food products. Scientific literature using phage preparations to control bacterial pathogens in postharvest foods have been cited by many and results of the studies were ample in demonstrating the efficacy of bactreiophages. In this review, we will provide studies generally describing the pathogen biocontrol by phages in postharves foods that do not undergo processing, such as fresh fruits and vegetables, meat and processed foods.

\section{PHAGES TO CONTROL FOODBORNE PATHOGENS IN FRESH FRUITS \& VEGETABLES}

Sharma et al., 2009 used a mixture of E. coli O157:H7-targetted bacteriophage to control E. coli on contaminated fresh cut lettuce and cantaloupe. Lettuce was treated by spraying, whereas cantaloupe was treated by application with a pipette Results showed a significant $(\mathrm{p}<0.05)$ reduction of $E$. coli on fresh cut cantaloupes inoculated with $E$. coli $\mathrm{O} 157: \mathrm{H} 7$. However, in fresh-cut lettuce spraying results in the greater reduction of viable Escherichia coli counts by $1.92 \mathrm{log} \mathrm{cfu} / \mathrm{cm}^{2}$. Greater reduction in lettuce by spraying may be due to improved contact between the phage and $E$. coli cells. In a similar study, Ferguson et al., 2013 evaluated phages to prevent cross contamination in fresh cut lettuce. Phage cocktail $\left(\right.$ EcoShield $\left.^{\mathrm{TM}}\right)$ was applied either by immersion or spraying. However the results showed that spraying phage cocktail on lettuce was more effective in reducing E. coli O157:H7 counts than immersion. In another study, Oliveira et al., 2014 investigated the phage Listex P100 efficacy against Listeria monocytogenes on fresh cut melon and pear slices stored at $10^{\circ} \mathrm{C}$. Phage treatment was successful in minimizing the levels of Listeria monocytogenes on melon and pear slices by about 1.5 and $1 \log \mathrm{cfu} / \mathrm{plug}$ No significant effect on apple slices was observed. This may be due to the acidic $\mathrm{pH}$ of apples, therefore, acid-tolerant phage must be used in apple slices to control L. monocytogenes on apple slices. Further, in a synergy study, Boyacioglu et al. 2016 demonstrated the synergy effect of phage cocktail (ListShield ${ }^{\mathrm{TM}}$ ) with atmospheric air and modified atmosphere to control L. monocytogenes on freshcut spinach leaves stored at 4 and $10{ }^{\circ} \mathrm{C}$. They found that the phage cocktail was effective in significantly reducing $L$. monocytogenes cells on the fresh cut spinach leaves under both atmospheric air and modified air conditions. Thus it can be concluded from the results that under commercial packaging conditions phage cocktail can be effective in reducing $L$. monocytogenes counts on fresh-cut green leafy vegetables.

\section{PHAGES TO CONTROL FOODBORNE PATHOGENS IN MEAT}

Scientific literature in the area of meat include studies by Hangaro et al., 2013 where a phage cocktail in synergy with the chemical agents like dichloroisocyanurate, peracetic acid and lactic acid was used to reduce $S$ enteritidis levels in chicken skin. Their results showed that the application of both phage cocktail and chemical agents reduce the $S$. enteritidis contamination by 1 lof $\mathrm{cfu} / \mathrm{cm}^{2}$ on the chicken samples. This further supports that phages should be used as an alternative biocontrol agent against Salmonella pathogen in poultry carcass industry. In another study, Zinno et al., 2014 assessed the antimicrobial ability of phage P22 on Salmonella enterica serovar Typhimurium contaminating chicken breast and chicken mince. Their results showed that when Salmonella Typhimurium was present at the concentration of $10^{4} \mathrm{UFC} / \mathrm{g}$, the use of phage resulted in the successful reduction of Salmonella strains on the chicken samples by 2-3 log cycles at $4{ }^{\circ} \mathrm{C}$ after $48 \mathrm{hrs}$. Liu et al., 2015 demonstrated the efficacy of four phages (T5, T1, T4 and O1) and a cocktail as biocontrol agents to reduce E.coli $\mathrm{O} 157$ on the beef samples stored at 4,22 and $37^{\circ} \mathrm{C}$. Results indicate that phages were more effective $(\mathrm{p}<0.001)$ in controlling the E.coli $\mathrm{O} 157$ population at warmer temperatures, thereby increasing the shelf life of beef samples prior to delivery to consumer. Phage biocontrol has also been shown to be effective when combined with modified atmospheric conditions, having better reductions in bacterial counts on chicken breast compared to their storage under aerobic conditions (Sukumaran et al., 2016). As modified atmosphere packaging is widely used by the various food industries, this observation has direct implication to improve product safety. Therefore, proper integration of phages in the existing Hazard Analysis and Critical Control Points (HACCP) protocols is key to it becoming an integral part of an effective multi-hurdle approach for improving food 
safety (Vikram et al., 2021). Recently, Grant et al., 2017 reported the effect of phage cocktail of 3 Salmonella strains on ground chicken. Chicken samples were inoculated with phage cocktail at the concentration of $4 \log \mathrm{CFU} / \mathrm{cm}^{2}$ using sterile tap or filtered water. Levels of Salmonella in ground chicken were significantly reduced by $0.39 \operatorname{logs}$ when using sterile tap water than $0.23 \mathrm{logs}$ in sterile filtered water. From the results, it was thus concluded that phage reduction mainly depends on the water that was used for diluting the bacteriophage.

\section{Phages to control foodborne pathogens in processed foods}

Processed foods like RTE meals, powdered infant formula, cheese, skimmed milk and energy drinks have always been associated with several foodborne outbreaks. Guenther et al., 2012 assessed the biocontrol ability of broad host range, virulent phage FO1-E2 against Salmonella Typhimurium in variety of RTE foods inoulated with $10^{3}$ viable Salmonella cells followed by treatment with $3 \times 10^{8} \mathrm{pfu} / \mathrm{g}$ phage. Results showed that complete inactivation of Salmonella was achieved in all cases especially during the first $24-48 \mathrm{~h}$ at both 4 and $15{ }^{\circ} \mathrm{C}$. However towards the end of incubation period some re-growth of the pathogen was observed. In another study, Zhang et al., 2013 used a single phage or a phage cocktail at the concentration of $10^{8}$ and $3 \times 10^{8} \mathrm{pfu} / \mathrm{g}$, respectively to reduce Shigella species on the RTE spiced chicken incubated at $4{ }^{\circ} \mathrm{C}$ for $72 \mathrm{~h}$. An effective reduction in the Shigella species was observed in the samples treated with single phage but the most effective results were obtained using phage cocktail, with complete eradication of Shigella species from the contaminated RTE chicken samples. Zinno et al., 2014 demonstrated the efficacy of temperate phage against Salmonella Typhimurium in whole and skimmed milk. Results indicate that the levels of the Salmonella were reduced to almost undetectable levels after phage treatment at $4{ }^{\circ} \mathrm{C}$. In case of the reconstituted infant milk formula, Kim et al., 2007 examined the biocontrol ability of two bacteriophages (ESP 732-1 and ESP 1-3) separately against Enterobacter sakazakki in reconstituted infant milk formula at different temperatures $(12,24$ and $37^{\circ} \mathrm{C}$ ). Results revealed that the application of both the phages can effectively reduce the growth of Enterobacter sakazakki counts in the formula at various temperatures. Thus, the results further support the use of combination of phages for the effective removal of such pathogen in the infant formulas.

\section{PHAGE APPROVALS}

Indeed, the United States Food and Drug Administration (US-FDA) has enumerated some bacteriophages with GRAS status, to prevent microbial (Escherichia coli, Listeria monocytogenes, Salmonella and so on) contamination on food products and food processing facilities (see Table 2). Towards the food safety perspective, the first OmniLytics Inc. produced phage-based product Agriphage $^{\mathrm{TM}}$, granted approval by the US regulatory agencies was listed for use in agriculture so as to treat plant pathogenic bacteria (US Environ. Prot. Agency, 2005). In 2006, Listshield ${ }^{\mathrm{TM}}$ was the first food safety related LMP-102 phage preparation, produced by the IntraLytics Inc. and approved by US-FDA as GRAS to control L. monocytogenes in RTE foods (Bren, 2007). Also the antilisterial activity of Listex P100 (phage P100) bacteriopage has been granted approval by US-FDA for the control of Listeria monocytogen stereotypes on the surface of raw salmon fillets (Soni and Nannapaneni, 2010). In 2007, a year later, in context to food safety, the use of the phage preparations like anti-E.coli and anti-Salmonella have received approval from the FDA, to decontaminate farm animals before slaughter (Garcia et al. 2010). EcoShield ${ }^{\mathrm{TM}}$ (using against E.coli) and SalmoFresh $^{\mathrm{TM}}$ (using against Salmonella) have received clearances in 2011 and 2013 respectively. Later on, numerous other bacteriophage preparations have been approved by US-FDA in the United States and in Canada, Australia, Germany, Switzerland by regulatory agencies.

Table 2 List of some phage preparations approved against a specific pathogen towards an increased food safety.

\begin{tabular}{lccc}
\hline Target & Phages & Approval date & Application \\
& ListShield & August, 2006 & RTE meats \\
cheese \\
Listeria monocytogenes & Listex $^{\mathrm{TM}}$ & October, 2006 & RTE meat, dairy, fish \\
& Listex $^{\mathrm{TM}}$ & September, 2010 & Meat, seafood, cheese, RTE foods \\
& Listex $^{\mathrm{TM}}$ & August, 2012 & Fruits, vegetables, dairy, fish \\
Escherichia coli & ListShield & January, 2015 & Ground beef \\
Salmonella & EcoShield $^{\mathrm{TM}}$ & February, 2011 & Ground beef \\
& Ecoshield $^{\mathrm{T}}$ & August, 2014 & Poultry, fish, fruits, vegetables \\
& SalmoFresh & February, 2013 & Pork and poultry \\
\hline
\end{tabular}

(Adapted and modified from Woolston and Sulakvelidze, 2015)

\section{CONCLUSION}

Bacteriophages are widely accepted as safe, green and viable alternative to traditional preservation methods for eliminating or significantly reducing the population of food-borne pathogens both pre-harvest and post-harvest. Towards an increased food safety perspective, phages can potentially be used as a means of biocontrol agents to prevent bacterial contamination in foods such as carcass, raw products and RTE products. As biosanitizing agents, bacteriophages could be used to disinfect equipments and food contact surfaces while as biopreservative agents, these can be used to kill food spoilage organisms and as phage therapy to reduce colonization during the primary production. Food producers are adopting phage biocontrol as part of a multiple hurdle approach to achieve a greater reduction in target pathogens and improve food safety. Moreover, a supportive consumer perception will likely further propel the adoption of phage biocontrol. The flexibility of commercial phage preparations from an application standpoint is helpful for food producers, as phages can be employed at either pre-harvest or postharvest stages, at a variety of processing steps, and through various mechanisms such as spraying, dipping, etc. The biggest advantage of using phage biocontrol is that wild type lytic phages are natural antimicrobials that allow targeted elimination of problem foodborne pathogens in foods without deleteriously impacting the natural microflora of foods and other nutritional or organoleptic qualities of foods. In developed countries, phage products are commercially available and have received approval for use by many regulatory agencies but insufficient phage biology knowledge at users end renders its use in developing countries. Therefore, utilizing phages at commercial level so as to diminish the remunerative load caused by bacterial contamination is worth considering. This brief review has highlighted recent advancements in the field, and it is clear from the literature that substantial research is still underway, some of which underscores the difficulty in creating dependable commercial phage products for food applications. In short, currently we have adequate expertise and equipment to address the technical challenges that prevent phage therapy from being widely used. As a result, it is only a matter of time before these flaws are addressed.

\section{REFERENCES}

Ackermann, H.W. (2006). 5500 Phages examined in the electron microscope. Archives of Virology, 152(2), 227-243. http://dx.doi.org/10.1007/s00705-006 0849-1

Ackermann, H.W. (2009). Phage Classification and Characterization Bacteriophages, 127-140. http://dx.doi.org/10.1007/978-1-60327-164-6 13

Ackermann, H.W., \& Prangishvili, D. (2012). Prokaryote viruses studied by electron microscopy. Archives of Virology, 157(10), 1843-1849. http://dx.doi.org/10.1007/s00705-012-1383-y

Adams, M. H. (1959). Bacteriophages. With chapters by E. S. Anderson [and others] Electron micrographs by E. Kellenberger http://dx.doi.org/10.5962/bhl.title.6966

Aksyuk, A. A., Leiman, P. G., Kurochkina, L. P., Shneider, M. M., Kostyuchenko, V. A., Mesyanzhinov, V. V., \& Rossmann, M. G. (2009). The tail sheath structure of bacteriophage T4: a molecular machine for infecting bacteria. The EMBO Journal, 28(7), 821-829. http://dx.doi.org/10.1038/emboj.2009.36

Atchley, C. (2019). Top trends driving the global food industry. 10th Jan 2019 https://www.foodbusinessnews.net/articles/13554-top-trends-driving-the-

globalfood-industry

Boyacioglu, O., Sulakvelidze, A., Sharma, M., \& Goktepe, I. (2016). Effect of a bacteriophage cocktail in combination with modified atmosphere packaging in controlling Listeria monocytogenes on fresh-cut spinach. Irish Journal of Agricultural and Food Research, 55(1), 74-79. http://dx.doi.org/10.1515/ijafr$\underline{2016-0007}$

Bren, L. (2007). Bacteria-Eating Virus Approved as Food Additive. FDA consumer, 41(1), 20-22

Bruttin, A., \& Brüssow, H. (2005). Human Volunteers Receiving Escherichia coli Phage T4 Orally: a Safety Test of Phage Therapy. Antimicrobial Agents and Chemotherapy, 49(7), 2874-2878. http://dx.doi.org/10.1128/aac.49.7.28742878.2005

Burmeister, A. R., Abedon, S. T., \& Turner, P. E. (2019). Bacteriophage Ecology. Reference Module in Life Sciences. http://dx.doi.org/10.1016/b978-0-12-809633 $\underline{8.90677-0}$

Carlton, R. M., Noordman, W. H., Biswas, B., de Meester, E. D., \& Loessner, M J. (2005). Bacteriophage P100 for control of Listeria monocytogenes in foods: Genome sequence, bioinformatic analyses, oral toxicity study, and application. 
Regulatory Toxicology and Pharmacology, 43(3), 301-312. http://dx.doi.org/10.1016/j.yrtph.2005.08.005

Cof fey, B., Mills, S., Coffey, A., McAuliffe, O., \& Ross, R. P. (2010). Phage and Their Lysins as Biocontrol Agents for Food Safety Applications. Annual Review of Food Science and Technology, 1(1), 449-468. http://dx.doi.org/10.1146/annurev.food.102308.124046

El-Shibiny, A., \& El-Sahhar, S. (2017). Bacteriophages: the possible solution to treat infections caused by pathogenic bacteria. Canadian Journal of Microbiology, 63(11), 865-879. http://dx.doi.org/10.1139/cim-2017-0030

Endersen, L., O’Mahony, J., Hill, C., Ross, R. P., McAuliffe, O., \& Coffey, A. (2014). Phage Therapy in the Food Industry. Annual Review of Food Science and Technology, 5(1), 327-349. http://dx.doi.org/10.1146/annurev-food-030713$\underline{092415}$

Fair, R. J., \& Tor, Y. (2014). Antibiotics and Bacterial Resistance in the 21st Century. Perspectives in Medicinal Chemistry, 6(14):2564. https://doi.org/10.4137/PMC.S14459

Ferguson, S., Roberts, C., Handy, E., \& Sharma, M. (2013). Lytic bacteriophages reduce Escherichia coliO157. Bacteriophage, 3(1), e24323. http://dx.doi.org/10.4161/bact.24323

García, P., Rodríguez, L., Rodríguez, A., \& Martínez, B. (2010). Food biopreservation: promising strategies using bacteriocins, bacteriophages and endolysins. Trends in Food Science \& Technology, 21(8), 373-382. http://dx.doi.org/10.1016/j.tifs.2010.04.010

Grant, A., Parveen, S., Schwarz, J., Hashem, F., \& Vimini, B. (2017). Reduction of Salmonella in ground chicken using a bacteriophage. Poultry Science, 96(8), 2845-2852. http://dx.doi.org/10.3382/ps/pex062

Guenther, S., \& Loessner, M. J. (2011). Bacteriophage biocontrol of Listeria monocytogenes on soft ripened white mold and red-smear cheeses. Bacteriophage, 1(2), 94-100. http://dx.doi.org/10.4161/bact.1.2.15662

Guenther, S., Herzig, O., Fieseler, L., Klumpp, J., \& Loessner, M. J. (2012) Biocontrol of Salmonella Typhimurium in RTE foods with the virulent bacteriophage FO1-E2. International Journal of Food Microbiology, 154(1-2), 6672. http://dx.doi.org/10.1016/j.ijfoodmicro.2011.12.023

Harada, L. K., Silva, E. C., Campos, W. F., Del Fiol, F. S., Vila, M., Dąbrowska, K., Balcão, V. M. (2018). Biotechnological applications of bacteriophages: State of the art. Microbiological Research, 212-213, 38-58. http://dx.doi.org/10.1016/j.micres.2018.04.007

Hanlon, G. W. (2007). Bacteriophages: an appraisal of their role in the treatment of bacterial infections. International Journal of Antimicrobial Agents, 30(2), 118128. http://dx.doi.org/10.1016/j.ijantimicag.2007.04.006

Hudson, J. A., Billington, C., Carey-Smith, G., \& Greening, G. (2005) Bacteriophages as Biocontrol Agents in Food. Journal of Food Protection, 68(2), 426-437. http://dx.doi.org/10.4315/0362-028x-68.2.426

Hungaro, H. M., Mendonça, R. C. S., Gouvêa, D. M., Vanetti, M. C. D., \& Pinto, C. L. de O. (2013). Use of bacteriophages to reduce Salmonella in chicken skin in comparison with chemical agents. Food Research International, 52(1), 75-81. http://dx.doi.org/10.1016/j.foodres.2013.02.032

Kim, K., Klump, J., \& Loessner, M. (2007). Enterobacter sakazakii bacteriophages can prevent bacterial growth in reconstituted infant formula. International Journal of Food Microbiology, 115(2), 195-203. http://dx.doi.org/10.1016/j.ijfoodmicro.2006.10.029

Kostyuchenko, V. A., Chipman, P. R., Leiman, P. G., Arisaka, F., Mesyanzhinov, V. V., \& Rossmann, M. G. (2005). The tail structure of bacteriophage T4 and it mechanism of contraction. Nature Structural \& Molecular Biology, 12(9), 810813. http://dx.doi.org/10.1038/nsmb975

Leiman, P. G., Arisaka, F., van Raaij, M. J., Kostyuchenko, V. A., Aksyuk, A. A., Kanamaru, S., \& Rossmann, M. G. (2010). Morphogenesis of the T4 tail and tail fibers. Virology Journal, 7(1) 355. http://dx.doi.org/10.1186/1743-422x-7-355 Leiman, P. G., Chipman, P. R., Kostyuchenko, V. A., Mesyanzhinov, V. V., \& Rossmann, M. G. (2004). Three-Dimensional Rearrangement of Proteins in the Tail of Bacteriophage T4 on Infection of Its Host. Cell, 118(4), 419-429. doi:10.1016/j.cell.2004.07.022

Lewis, R., \& Hill, C. (2020). Overcoming barriers to phage application in food and feed. Current Opinion in Biotechnology, 61, 38-44. https://doi.org/10.1016/j.copbio. 2019.09.018

Leiman, P. G., \& Shneider, M. M. (2011). Contractile Tail Machines of Bacteriophages. Advances in Experimental Medicine and Biology, 93-114. https://doi.org/10.1007/978-1-4614-0980-9 5

Liu, H., Niu, Y. D., Meng, R., Wang, J., Li, J., Johnson, R. P., \& Stanford, K. (2015). Control of Escherichia coli $\mathrm{O} 157$ on beef at 37, 22 and $4{ }^{\circ} \mathrm{C}$ by T5-, T1-, T4-and O1-like bacteriophages. Food Microbiology, 51, 69-73. https://doi.org/10.1016/j.fm.2015.05.001

Mahony, J., McAuliffe, O., Ross, R. P., \& van Sinderen, D. (2011). Bacteriophages as biocontrol agents of food pathogens. Current Opinion in Biotechnology, 22(2), 157-163. https://doi.org/10.1016/j.copbio.2010.10.008

Maura, D., \& Debarbieux, L. (2011). Bacteriophages as twenty-first century antibacterial tools for food and medicine. Applied Microbiology and Biotechnology, 90(3), 851-859. https://doi.org/10.1007/s00253-011-3227-1
Moye, Z., Woolston, J., \& Sulakvelidze, A. (2018). Bacteriophage Applications for Food Production and Processing. Viruses, 10(4), 205 https://doi.org/10.3390/v10040205

Oliveira, M., Viñas, I., Colàs, P., Anguera, M., Usall, J., \& Abadias, M. (2014). Effectiveness of a bacteriophage in reducing Listeria monocytogenes on fresh-cut fruits and fruit juices. Food Microbiology, 38, 137-142. https://doi.org/10.1016/j.fm.2013.08.018

Orlova, E. V. (2012). Bacteriophages and Their Structural Organisation. In Bacteriophages I. Kurtboke (Ed), pp. 3-30, IntechOpen https://doi.org/10.5772/34642

Sillankorva, S. M., Oliveira, H., \& Azeredo, J. (2012). Bacteriophages and Their Role in Food Safety. International Journal of Microbiology, 2012, 1-13. https://doi.org/10.1155/2012/863945

Sciara, G., Bebeacua, C., Bron, P., Tremblay, D., Ortiz-Lombardia, M., Lichiere, J., \& Cambillau, C. (2010). Structure of Lactococcal phage p2 baseplate and its mechanism of activation. Proceedings of the National Academy of Sciences, 107(15), 6852-6857. https://doi.org/10.1073/pnas.1000232107

Sharma, M., Patel, J. R., Conway, W. S., Ferguson, S., \& Sulakvelidze, A. (2009) Effectiveness of Bacteriophages in Reducing Escherichia coli O157:H7 on FreshCut Cantaloupes and Lettuce. Journal of Food Protection, 72(7), 1481-1485. https://doi.org/10.4315/0362-028x-72.7.1481

Smith, H. L., \& Trevino, R. T. (2009). Bacteriophage Infection Dynamics: Multiple Host Binding Sites. Mathematical Modelling of Natural Phenomena 4(6), 109-134. https://doi.org/10.1051/mmnp/20094604

Sohaib, M., Anjum, F. M., Arshad, M. S., \& Rahman, U. U. (2015). Postharvest intervention technologies for safety enhancement of meat and meat based products; a critical review. Journal of Food Science and Technology, 53(1), 19-30. https://doi.org/10.1007/s13197-015-1985-y

Soni, K. A., \& Nannapaneni, R. (2010). Bacteriophage Significantly Reduces Listeria monocytogenes on Raw Salmon Fillet Tissue. Journal of Food Protection, 73(1), 32-38. https://doi.org/10.4315/0362-028x-73.1.32

Sukumaran, A. T., Nannapaneni, R., Kiess, A., \& Sharma, C. S. (2016). Reduction of Salmonella on chicken breast fillets stored under aerobic or modified atmosphere packaging by the application of lytic bacteriophage preparation SalmoFreshTM. Poultry Science, 95, 668-675. https://doi.org/10.3382/ps/pev332 Sulakvelidze, A. (2013). Using lytic bacteriophages to eliminate or significantly reduce contamination of food by foodborne bacterial pathogens. Journal of the Science of Food and Agriculture, 93(13), 3137-3146. https://doi.org/10.1002/jsfa.6222

US Environmental Protection Agency. (2005). Xanthomonas campestris pv. vesicatoria and Pseudomonas syringae pv. tomato specific bacteriophages; exemption from the requirement of a tolerance. Federal Register 70(248), 7670076704. https://www.govinfo.gov/content/pkg/FR-2005-12-28/pdf/05-24540.pdf Vikram, A., Woolston, J., \& Sulakvelidze, A. (2021). Phage biocontrol applications in food production and processing. Current Issues in Molecular Biology, 40, 267-302. https://doi.org/10.21775/cimb.040.267

Weinbauer, M. G. (2004). Ecology of prokaryotic viruses. FEMS Microbiology Reviews, 28(2), 127-181. https://doi.org/10.1016/j.femsre.2003.08.001

Wittebole, X., De Roock, S., \& Opal, S. M. (2013). A historical overview of bacteriophage therapy as an alternative to antibiotics for the treatment of bacterial pathogens. Virulence, 5(1), 226-235. https://doi.org/10.4161/viru.25991

WHO. (2020). Food Safety, Key facts. Accessed on 30 April 2020. Accessed via https://www.who.int/health-topics/foodborne-diseases\#tab=tab 1

Wommack, K. E., \& Colwell, R. R. (2000). Virioplankton: Viruses in Aquatic Ecosystems. Microbiology and Molecular Biology Reviews, 64(1), 69-114. https://doi.org/10.1128/mmbr.64.1.69-114.2000

Woolston, J., \& Sulakvelidze, A. (2015). Bacteriophages and food safety. John Wiley \& Sons. https://doi.org/10.1002/9780470015902.a0025962

Zhang, H., Wang, R., \& Bao, H. (2013). Phage inactivation of foodborne Shigella on ready-to-eat spiced chicken. Poultry Science, 92(1), 211-217. https://doi.org/10.3382/ps.2011-02037

Zinno, P., Devirgiliis, C., Ercolini, D., Ongeng, D., \& Mauriello, G. (2014). Bacteriophage P22 to challenge Salmonella in foods. International Journal of $\begin{array}{llr}\text { Food Microbiology, } & 191, & 69-74\end{array}$ https://doi.org/10.1016/j.ijfoodmicro.2014.08.037 